\title{
Teachers' Perception towards the Use of Quipper School in Teaching English
}

\author{
Dewi Amalia Saptani \\ Universitas Negeri Semarang, Semarang, Indonesia \\ dewi.amalia13@gmail.com
}

\begin{abstract}
Rapidly developing technology plays an important role in the innovation of education. Learning Management System (LMS) websites are one of the most recent innovations. This study investigates teachers' perception towards the use of Quipper School (QS), one of popular LMS websites in teaching English. A semi-structured interview was designed to find out how three English teachers in Indonesia perceive the use of the media. To analyze the obtained data from the interview, qualitative content analysis was used. The results show that the participants have positive attitude towards the use of QS. Technically, QS is perceived to be a good and motivating ELT media. However, QS has not been designed to facilitate the teaching of speaking.
\end{abstract}

Keywords: Innovation, QS, English Language Teaching, Content Analysis

\section{INTRODUCTION}

As Information and Communication Technology (ICT) is advancing rapidly, new technology and innovation in teaching and learning have developed accordingly. Joe and Chol (2002) argue that new technology systems and instruments are becoming more and more common and being used for the benefits of educational activities The innovation concerning educational activities brings about opportunities for teachers and students to experience teaching and learning beyond traditional classrooms, that is through ComputerAssisted Language Learning (CALL). One of the most wellknown CALL media is Learning Management System (LMS)

Learning Management System (LMS) is describes as an online learning platform or software that is devised to organize and manage learning (Anderson, 2008; Paulsen, 2003). Further, Paulsen (2003) describes three fundamental features of an LMS namely the creation of course tools, teacher and student support tools, and administrative system. The creation of course tools are features that enable the users of LMS to create learning materials, develop learning modules, and arrange group works. Teacher and student support tools provide access to learning materials and facilitate teacher-students and student-student communication. Administrative system includes features for registration, course enrollment, and grouping students.

One of the most recently established and popular LMS is The Quipper School (henceforth QS). Quipper School is a web-based online learning website and application that is originally developed by Quipper Ltd. in London and available online at http://school.quipper.com. QS has been widely used by teachers and students around the world including those in Indonesia. A research investigating the affordability of QS reveals that QS has at least three features that other LMS platforms such as Moodle and Claroline do not have. First, QS does not require installation on an existing hosting site. It provides teachers and students with a ready-touse web-based learning application. Secondly, QS provides teachers with virtual storage that allows them to upload and keep their teaching materials and media such as PowerPoint presentations, PDF files, pictures, and videos. Thirdly, the storage available on the website helps the teachers to maintain their teaching and learning activity records, thus they can monitor students' learning activity. Having those excellent features, QS is gaining huge popularity among teachers and students. However, the use of QS has not been as popular as it is in other countries such as United Kingdom, Philippines, and Mexico.

In terms of English Language Teaching, Chapelle (2003) suggests three conditions of CALL pedagogy that English teachers should take into consideration when incorporating technology into language learning classrooms; they are the availability of L2-input exposure, interaction and linguistic production. Regarding the availability of L2 input, Chapelle (2003) further suggest that the use of computer technology in the classroom should bring benefit to learners through enhanced linguistic input. The three types of language input suggested by Chappelle are salience (e.g. interaction with a grammar application), modification (providing any means that help learners to arrive at the meaning, such as through images), and elaboration (providing explanations). QS provides these three types of enhanced learning input.

As a web-based learning platform, QS offers learners multimodal exposure (written, aural and visual) for foreign language input. For example, teachers can develop learning materials that are enriched by visual and audio media, such as text with illustration, images, videos or other multimedia resources. Unfortunately, QS is not enhanced with a speech recognition technology, a technology that can identify or recognize words or spoken expressions. Such an absence reduces an opportunity for the students to interact with the computer verbally, thus, the learning of speaking is not feasible for the students.

In terms of interaction, QS gives teachers and students an opportunity to get engaged into interpersonal communication. The 'message' and 'announcement' features help teachers to interact with colleagues and students. In addition, teachers can work collaboratively with their colleagues when developing a learning curriculum, or can design lessons (assignments) for the pupils together. To do this, teachers initially need to invite colleagues into their classroom through the Teacher Page, via email or on the Class Page. 
Concerning the language production, in QS, students' linguistic production is facilitated through the assignment feature. Unfortunately, production is limited to aspects of students' writing skills such as vocabulary and grammar. Question types in the QS assignment system include a single answer, multiple answers, correct values, correct order, and categorize answer questions

However, even though technically QS is considered beneficial for English Language Teaching, the real implementation of the media has not been revealed, especially in Indonesian context. This study is designed to explore how English teachers in Indonesia utilize QS as one of their teaching media and reveals their perception towards the use of the media. Thus, the objectives of the study is to explain Indonesian English teachers' perception towards the use of QS in the process of teaching and learning English.

\section{METHODOLOGY}

\subsection{Research Design}

To answer the formulated research question, this study employs case study research method. Cohen (2007) describes case study as a research method that focuses on individual actors or group of actors and seek to understand their perceptions of events. This is in line with the objective of current study, that is to explain teachers' perception on the use of Quipper School in teaching English.

\subsection{Site and Participants}

The study was conducted in Semarang, Central Java, Indonesia involving three English teachers. Regarding the selection of participants, the study use purposive sampling. This sampling strategy is used in which the selected participants need to meet a particular characteristic, that is they use QS as one of their teaching media.

\subsection{Data Collection and Analysis}

To collect the data needed to answer the research question, the researcher used observation and interview. The observation was done once for every teacher to see how they use QS as their teaching media. The researcher took some field notes during the observation. The interview was administered to explore teachers' perception on the use of QS. It included 16 open-ended questions focusing on participants' experience in using QS. The whole data of the research are in the form of words. This is in line with Robson (2002) as cited in Cohen (2007) that stated that case studies opt for analytic rather that statistical generalization. Thus, the obtain data then analyzed in the form of descriptive explanation.

\section{RESULTS AND DISCUSSION}

Content analysis was employed to analyzed and evaluate the data gained from the interview of the three teachers. Two themes were developed based on the content of the interview namely feature of QS and QS in teaching English.

\subsection{Features of QS}

First part of the interview focuses on investigating teachers' knowledge and ability in using technology, especially those used for teaching. The obtained data suggest that the participants use computer-assisted media in their teaching process frequently. To all participants generally, there are several factors to consider in using computerassisted media namely the material being taught and school policy on the use of such media. Almost all topics of English in every level of education can be presented through computer-assisted media. One of the participants says that she thinks it is helpful to use such media in helping students to comprehend the material, she uses the media. Another participant implies that the school where she works for is a sufficiently equipped school, therefore she is strongly advised to use computer-assisted media.

QS as one of computer-assisted media has gain a huge popularity among educators and students. The participants commonly know QS from their fellow teachers. Regarding the frequency of using QS, Glgenerally, the participants use QS whenever the internet connection is available for the students and most of the time outside the class. A participant adds that whenever she could not come to the class, she asks her students to read materials from the website or application and do the exercise available there. Participants use QS to enrich and vary their teaching materials and teaching assignments for the students

To use QS in teaching and learning process, users need to choose role in the time of account registration whether they are teachers or students. Different roles provide different access to QS fearures. The 'teacher role' enables teachers to have full access to QS's three main features namely 'creation', 'assessment', and 'learning'. The role also grants teachers access to 'overview', 'assignments', 'curriculum', 'message' and 'manage' menus. The 'overview' menu provides brief information about active assignments submitted by the students and students' individual performances. The 'assignment' menu allows teachers to create new assignments, distribute them to students and monitor their progress. The 'curriculum' menu offers two options for teachers regarding the learning materials; they can either use the materials available on QS database, or they can develop their own materials and use them to teach their students. The 'message' menu has two functions; firstly, it facilitates teacher-student communication, and, secondly, it allows teachers to distribute notes to all students. Finally, the 'manage' menu allows teachers to select course participants, group the students, and invite other colleagues to teach collaboratively within the virtual classroom.

Given access to those five features of QS, the three participants argues that the most useful feature of QS is the Assignment menu, since it provides a lot of exercises for the students to practice. In addition, concerning the teaching materials, teachers can either use the available materials provided by QS or develop or upload their own materials. 
Having provided the materials by the website, the participants say that the materials are good and helpful. However, sometimes they combine the available materials with those they make to enrich and vary the materials.

When asked how QS is suitable to use as teaching media with students nowadays, the participants have similar idea that this technology suits the students in this modern era in two ways. First, students are familiar with the use of smartphones and personal computers. They are skillful enough to work with such media. Therefore it is feasible for them to use QS. Second, engaging students with online learning will increase their motivation, since learning through QS allow them to use tools that they generally like i.e. smartphones and computers. Regarding the most suitable students' level to implement QS with, the participants commonly suggest that the most appropriate learners to work with this application are those in senior high school and university level. In terms of students' observed response towards the use of QS, the participants say that their students are interested and enthusiast in using the media.

Drawing on their experience of using QS, the teachers commonly summarized three drawbacks of QS. Firstly, QS is an internet=dependent media. Thus, Internet connection is the main problem in utilizing the media. Secondly, extended use of online class reduces students' actual interaction both with teacher and their peers, in other words, the students interact only with gadgets. Finally, On one hand, QS provides a wide range of teaching materials and becomes potential alternative teaching media. On the other hand, to use this media, teachers and students need smartphones or personal computers which are not always available.

\subsection{QS in Teaching English}

The three participants agree that the most feasible language skills to be improved using QS are reading and writing. This is in line with the fact that QS is not equipped with voice recognition technology, thus it could not facilitate the learning of speaking. However, the platform provides the students with an enormous amount of materials to practice their skill of reading, writing, and even listening. In addition, it exposes the students to a wide range of English vocabularies. In addition, QS allows interactions both between teacher and students and among students in which they can communicate using English. So, technically, QS is perceived to be a good media in teaching English.

\section{CONCLUSION}

This study aims to explain English teachers; perception towards the use of Quipper School in teaching English. The results of interview data analysis show that the participants commonly agree on and encourage the use of QS in teaching since it provides a great amount of alternative material, promote interactions and increase students' motivation. However, QS is an internet-dependent media. Thus, itcould not be use with the absence of internet connection. More importantly, it has not been design to facilitate the teaching of speaking. Further research can focus on the effectiveness of QS in teaching writing.

\section{REFERENCES}

Anderson, T. (Ed.). (2008). The theory and practice of online learning. Edmonton: AU Press

Chapelle, C. (2003). English language learning and technology: Lectures on Applied Linguistics in the Age of Information and Communication Technology (Vol. 7). Amsterdam, Philadelphia: John Benjamins Publishing.

Cohen, L. et. al. (2007). Research method in education. New York. Rouledge.

Joo, Y, J. Bong ve H.J. Chol (2002); Self-Effiacy for selfregulated learning,academic self-effiacy and internet selfeffiacy in Web based instruction. ETR\&D,Cilt.48,No.2, 2000, 5-17.

Paulsen, M. F. (2003). Experiences with learning management systems in 113 European institutions. Journal of Educational Technology \& Society, 6(4), 134-148. 